\title{
Influence Of Hiv/Aids Education On Behavioural Changes Selected Among Tertiary Education Institution Students In Ondo State, Nigeria.
}

\author{
Ajibade B.L. RN, Phd. FWACN, MCAN; Makanjuola O.J. RN, RPHN, BNSC \\ Department of Nursing, C.H.S. LAUTECH, Osogbo. \\ Ondo State School of Nursing, Igbatoro Road, Akure, Ondo State.
}

\begin{abstract}
IntroductioN - Concerns about infection with Human Immune Deficiency Virus (HIV) among the young people have renewed interest in developing countries, where they represent a large proportion of population and are at high risk. The study examined the influence of the HIV/AIDS education on behavioural change among tertiary students in Ondo State, Nigeria.

Methodology - Multistage sampling technique was used sample size of 276 students were selected. Three research questions and one hypothesis guided the study at $P \leq 0.05$. The study was a descriptive survey on tertiary students in Ondo State. The instruments was a 28 item questionnaire which was duly validated by an experts in the field.

Result - Inferential statistic was used to test the hypotheses while frequency counts and percentage were used in describing the demographic profile and answering the research questions. The results from the study revealed that the students' knowledge about HIV/AIDS was high but their behaviour changes were not encouraging as about (47\%) found it difficult to avoid pre-marital sex and only $43 \%$ would limit sex to one partner. It was clear that Youths have very high knowledge of key basic concept on HIV/AIDS but many youths have misconceptions about cure of AIDS.

Conclusion - It was conducted that efforts should be made by governmental and non-governmental organizations to help students meet the challenges of HIV/AID. It was recommended that policies and programmes that can transform the sexual life of youths or reduce their risk behaviour should be put in place while prevention message should be consistent clear and effective to counteract other reliable sources of information.
\end{abstract}

Key Words: Influence, HIV/AIDS, Education, Behavioural change, Tertiary Institution, Coitus.

\section{Introduction}

HIV/AIDS has become one of the most devastating diseases humanity has ever faced. It has become a major public health cancer with about half of new infections occurring in young people. Human immunodeficiency virus (HIV) and acquired immune - deficiency syndrome (AIDS) have been a threat to human life for almost three decades worldwide. The number of people living with HIV has risen from around eight (8) million in 1990 to thirty-three 33 million (United Nations AIDS (UNAIDS) Report, 2008).

HIV/AIDS pandemic has accounted for the death of men, women and orphaned children worldwide. It was estimated that cumulative deaths from AIDS would be between 3.6 and 4.2 million people (Mental Health AIDS, 2007). The epidemic of HIV continues to grow in Nigeria despite efforts to control it. According to UNAIDS (2012), about 700,000 young people aged 15-32 were with HIV an number nearly one fifth of the total population of HIV - positive in Nigeria (UNAIDS, 2012). The majority of tertiary students fall in this age group.

Tedro (2001), Utuka and Ezeochi (2005), Action AIDS (2006) and Omotose et al (2010), identified the major means of transmission to include:

- Unprotected penetrative sexual contact and other risk behaviour which account for $80 \%$ of cases of HIV/AIDS infection.

- Blood transfusion with contaminated blood of a donor.

- Blood from an infected person entering a cut or an open wound on another person.

- Mother to child either before, during or after birth and

- Using unsterilized hypodermic needles and syringes.

According to Selgson and Peterson (1992) many students enrolled in universities are between the 15 and 30 years. This age is traditionally a time of sexual experimentation and sexual irresponsibility when they feel relatively immortal, and immune to the ravages of disease or accident. Most first year university students are vulnerable, as they will be away from behavioural constraints of home for the first time. In Nigeria, the predominant mode of HIV transmission is sexual contact, accounting for about $80 \%$ of the HIV infections 
(Omotose et al. 2010). Jackson (2002), states that the risk of infection increases with the number of sexual partners a person has an by the actual sexual behaviour with each partner.

Omotose et al (2010), opined that in the absence of credible curative drugs and vaccines, the only way currently available for dealing on a large scale with HIV/AIDS is through developing appropriate standard of behaviour which can only be achieved through the proper knowledge of HIV/AIDS. Sexual behaviour change remains the most effective way to preventing transmission among the university students.

The findings from Adedimeji (2003), revealed that awareness of HIV/AIDS transmission dynamics among tertiary students is generally high but behavioural change relative to the epidemic is very limited in Nigeria. In practice, as noted by Seligson and Peterson (1992), a person's level of knowledge about AIDS does not necessarily result in a change of behaviour. Considering that the students in tertiary institutions are young adults, most of them were not married and fall in the sexually active group, it may follow that they stand the greatest risk of contracting the HIV virus with the economic problems in Nigeria. There are high chances that some students may engage in risky sexual behaviour in exchange for money, food and accommodation. In Ondo State according to data gathered from various specialist hospitals it shows that there were new cases being diagnosed on daily basis age range with in the study group. Taking this into consideration the study sought to find out if the knowledge of HIV/AIDS acquired by the students has any impact on their risky behaviour.

\section{Objectives}

The main objective of this study was to find out the influence of HIV/AIDS education received had changes students' behaviour as regards HIV/AIDS infection among the university students in Ondo State.

The specific objectives are:

1. To find out what the students know about HIV/AIDS

2. To determine factors influencing behavioural changes among the students.

3. To identify methods using by the students to prevent HIV and AIDS infection.

\section{Research Questions}

The following were the research question to guide the study.

1. What is the level of respondents knowledge towards HIV/AIDS?

2. What are factors influencing behavioural changes among the respondents?

3. What are preventive measures adopted before respondents during coitus?

\section{Research Hypothesis}

One null hypothesis was tested at the 0.05 level of significance.

Ho: There is no significant association between students knowledge on HIV/AIDS and the behavioural changes in relation to HIV/AIDS.

\section{Methodology}

Study Design: A descriptive study was adopted to assess the influence of HIV/AIDS education on behavioural changes among tertiary students in Ondo State. This design was used as the researcher were not ready to manipulate variables in the study but would be described as they occurred in the study.

Study Population: The target population was students in Federal University of Technology Akure (FUTA) Ondo State, Nigeria, which was randomly selected from five public tertiary institutions in Ondo State.

\section{Sample and Sample Technique}

A total of 280 university students were randomly selected proportionate to the number of students in 8 various departments of school of Agric and Agricultural Technology.

Sampling technique for this study was a multistage sampling technique. The total number of students in Federal University of Technology Akure (FUTA) was 13246 as at time of study. Clustering was done for schools size. Including school of science, school of earth and mineral science, school of agriculture, school of engineering, school of environmental technology, school of management technology, school of Agric and Agricultural Technology was randomly selected for the study. Total 276 students were randomly selected proportionate to the number of students in each department. Department of Agric Economic and Extension (with population of 429 students has 62), department of Animal Production and Health $(n=344, n=50)$, department of Crop, Soil and Pest Management $(n=301, n=43)$, department of Ecotourism and Wildlife Management ( $\mathrm{n}$ $=480, n=47)$, department of Forestry and Wood Technology $(n=496, n=49)$, department of Food Science and Technology $(n=485, n=47)$, and Department of Fisheries and Agriculture Technology $(n=262, n=371)$. Research Instrument: Researchers developed questionnaire consisting of twenty-eight (28) items were used. The questionnaire was divided into four (4) sections. Section one contains demographic information of the respondents while section two contains information on the knowledge of students on HIV/AIDS, section three 
contains information on the factors influencing the student's change in behaviour while section four contains information on the preventive measures used by the students. The respondents were required to either choose from the list of supplied option or fill in the needed information.

Validity and reliability: The instrument was given to expert in the study area; for both face and content validity. The instrument was modified according to the recommendations of the experts. To ensure consistency of the instrument, a test-retest within an interval of three weeks was conducted in another tertiary institution of Ondo State, Nigeria. A test and retest reliability was 0.78 and $0-81$ respectively.

Data Collection Procedure: Data for the study were collected using self designed structured questionnaire. The questionnaire were distributed to all respondent and 276 out of 280 questionnaire were retrieved from the respondents. The questionnaire has four sections.

Research Ethics: Approval for the study was obtained from Federal University of Technology ethical committee after the submission of the research instruments. Respondents participated in completing the questionnaires voluntarily after being informed of the purpose of the study and verbal consent obtained. Confidentiality was assumed by using numbers on the questionnaires.

Data Analysis: Statistical analysis was carried out using the statistical product and services solution (SPSS) version 20 for windows. Frequencies and percentages were used as descriptors of the sample. One-way Anova statistics was used to test for significance at 5\% probability level.

\section{Results}

TABLE 1: Socio-demographic profile of respondents.

\begin{tabular}{|l|l|l|}
\hline VARIABLES/ITEMS & FREQUENCY & PERCENTAGE (\%) \\
\hline SEX & & \\
\hline Male & 153 & 55.4 \\
Female & 123 & 44.6 \\
Total & 276 & $\mathbf{1 0 0}$ \\
\hline AGE: YEARS & & \\
\hline $14-18$ & 66 & 23.9 \\
$19-22$ & 168 & 60.9 \\
$23-28$ & 42 & 15.2 \\
Total & $\mathbf{2 7 6}$ & $\mathbf{1 0 0}$ \\
\hline MARITAL STATUS & & \\
\hline Single & 266 & 96.4 \\
Married & 10 & 3.6 \\
Total & $\mathbf{2 7 6}$ & $\mathbf{1 0 0}$ \\
\hline RELIGION & & \\
\hline Christianity & 231 & 83.7 \\
Islam & 45 & 16.3 \\
Total & $\mathbf{2 7 6}$ & $\mathbf{1 0 0}$ \\
\hline DEPARTMENTS & & \\
\hline Fat & 37 & 13.3 \\
Fst & 50 & 18 \\
Fwt & 30 & 10 \\
Ewm & 27 & 9.7 \\
Csp & 39 & 14 \\
Ace & 53 & 19 \\
Aph & 40 & 14 \\
Total & $\mathbf{2 7 6}$ & $\mathbf{1 0 0}$ \\
\hline LEVEL & & 80 \\
\hline 100 & 180 & 10 \\
200 & 35 & $\mathbf{1 0 0}$ \\
300 & 61 & \\
Total & $\mathbf{2 7 6}$ & \\
\hline & & \\
\hline
\end{tabular}

Table 1, shows the socio-demographic characteristics of respondents. The overall mean age of the respondents was 20.25 with $+2.34 \mathrm{SD}$ and ranged from 14 to 26 years. Out of the 276 respondents, $153(55.4 \%)$ were male and $123(44.6 \%)$ were female. Only $10(3.6 \%)$ of the subjects were married. More than $82 \%$ of the respondents were Christian; also $64.82 \%$ of the respondents were in 100 level as at time when these data were collected.

TABLE 2: What is the level of respondents knowledge on HIV/AIDS 
Influence Of Hiv/Aids Education On Behavioural Changes Selected Among Tertiary Education

\begin{tabular}{|c|c|c|c|c|}
\hline \multirow[b]{2}{*}{ Category } & \multicolumn{2}{|c|}{ Yes } & \multicolumn{2}{|c|}{ No } \\
\hline & Freq & $\%$ & Freq & $\%$ \\
\hline Have you attend any workshop/seminar on HIV/AID & 269 & 97.56 & 7 & 2.50 \\
\hline Is there any vaccine against AIDS & 95 & 34.40 & 181 & 65.60 \\
\hline Do you think AIDS can be cured & 135 & 48.90 & 141 & 51.10 \\
\hline Do you think multiple sexual partners are at high risks & 239 & 86.60 & 37 & 12.40 \\
\hline Can IV drug users be at high risk & 104 & 37.70 & 95 & 34.4 \\
\hline Can HIV/AIDS be transmitted through blood transfusion & 237 & 85.60 & 39 & 14.10 \\
\hline Can HIV/AIDS be transmitted through sexual intercourse & 252 & 91.30 & 24 & 8.70 \\
\hline Can HIV/AIDS be transmitted by injection/sharing of needles & 251 & 90.90 & 25 & 9.10 \\
\hline Can HIV/AIDS be transmitted through breast feeding & 86 & 31.20 & 190 & 68.8 \\
\hline
\end{tabular}

Table 2, shows distribution frequency of respondents knowledge. Virtually all $(97.50 \%)$ of the respondents had heard about HIV/AIDS. The majority (91.3\%) knew that HIV could be transmitted through sexual intercourse with infected person, blood transfusion (85.6\%) and through injection and sharing of needles with infected person (90.9\%). About $34 \%$ believe that there were vaccine for HIV/AIDS, on the other hand, 48.9\% believed that HIV/AIDS has a cure while $68.8 \%$ did not know that HIV could be transmitted through breastfeeding.

TABLE 3: What are factors influencing behavioural change among respondents?

\begin{tabular}{|l|l|}
\hline VARIABLES & PERCENTAGE (\%) \\
\hline Knowledge of HIV/AIDS & $48(132)$ \\
\hline Fear of dying & $67(186)$ \\
\hline Stigmatization & $38(106)$ \\
\hline Fear of being infected & $77(212)$ \\
\hline Seeing and HIV infected person & $65(182)$ \\
\hline HIV/AIDS awareness programme & $23(62)$ \\
\hline
\end{tabular}

Table 3, shows the factors influencing behaviour changes among the respondents in relation to HIV/AIDS. The knowledge of HIV/AIDS of the respondents were $48 \%, 67 \%$ were influenced by fear of dying, $77 \%$ were influenced to changed by fear of being infected, $65 \%$ were influenced by seeing an HIV infected person while $38 \%$ and $23 \%$ of the respondents were influenced by stigmatization and HIV awareness programme respectively.

There is no association between student knowledge on HIV/AIDS and their behavioural changes in relation to HIV/AIDS.

TABLE 4: Association between student knowledge on HIV/AIDS and their behavioural changes in relation to HIV/AIDS.

\begin{tabular}{|l|l|l|l|}
\hline Responses & DF & F & Significant \\
\hline Students & 1 & & \\
\hline Behaviour as regards to HIV/AIDS & 274 & 1.130 & 0.298 \\
\hline
\end{tabular}

A one way ANOVA was conducted to compare the knowledge on HIV/AIDS and their behavioural changes in relation to HIV/AIDS. There was no statistically significant difference between the knowledge on HIV/AIDS that student had received and the behaviours to the HIV/AIDS infection at the $\mathrm{P}<0.05$ level as determined by one way Anova $[\mathrm{F}\{1,274)=1.130, \mathrm{P}=0.298]$.

It can be concluded that despite the high knowledge of students about the causes, mode of transmission and prevention. Many of them still were at risk of contracting the HIV as more than $50 \%$ students still have multiple sex partners.

TABLE 5: What types of Preventive Measures are adopted by respondents during coitus?

\begin{tabular}{|l|l|}
\hline VARIABLES & PERCENTAGE (\%) \\
\hline Limit sex to one partner & $43(1180$ \\
\hline Used condoms during sex & $61(170)$ \\
\hline Can abstain from sex until marriage & $53(146)$ \\
\hline Avoid sex with prostitutes & $72(201)$ \\
\hline Avoid sex with person with many partners & $73(202)$ \\
\hline Avoid sharing razor blades, needles and other sharp objects & $70(193)$ \\
\hline
\end{tabular}

Table 5 , shows that $61 \%$ of respondents were using condoms during sexual intercourse, $43 \%$ limited sex to only one partner, about $72 \%$ would not have sex with prostitute and $73 \%$ of the respondent would not have sex with person with many partners, while $70 \%$ would not share razor blades, needles and other sharp objects with others.

Abstinence for HIV prevention appears to be difficult for students. forty-seven percent (47\%) of the respondent indicated that it was difficult for them to abstain from sex. 


\section{Discussion}

The study was carried out to find out the influence of HIV/AIDS knowledge on behaviour change among tertiary students in Ondo State, Nigeria. The results of the study showed that the University students' knowledge about HIV/AIDS was high and the percentage of misconceptions was low, this is because many of them know ways of contracting HIV/AIDS. This finding is in line with Gulure (2003) and Omoteso et al (2010) who found out that young people were aware of the means of transmission of HIV/AIDS. This is also consistent with the result of other studies on college students (Svenson, 1990' Green 1991; Singh, 2005; Zikifli, 2002) who stated that the level of knowledge among university students was high. However, there are still some misconceptions about the route of transmission and preventive measures. For instance, $69 \%$ of students did not consider breastfeeding as a route of HIV infection. Forty-nine percent though that AIDS could be cure. This is fully supported by Ogundana, (2002) who reported that nearly all respondents got to know about HIV/AIDS through information provided by government and non-governmental agencies. However, the message appears less effective in depicting AIDS particularly as an incurable disease.

Contradictory, poor level of knowledge was reported in many studies inclusive of Macedonia (Atanasova, 2004), on the other hand, high level of knowledge of HIV was reported among the students in other studies for instance Jamacia (Robilland, 2001).

The study further showed that the factors that influenced behavioural change among tertiary students as regards HIV/AIDS were knowledge of HIV/AIDS, fear of being infected which came first in the list with the highest percentage. Fear of dying also came seemed in the list with the second higher percentage; others include seeing an HIV infected person, stigmatization and HIV/AIDS awareness programme. This result was in line with Anyamene, Nwokolo, Anyachebelu and Okeke (2011) who stated young people are always afraid to die believing that old people should die first. This forgetting that death is for all irrespective of age. Also seeing an infected person especially one that is already down with. AIDS sets up a type of latent fear of being infected in them.

Findings from the study also showed non-significant difference in the students' knowledge of HIV/AIDS and their behaviour change. This may be due to the fact that individuals, especially young people (students) find it easy to internalize knowledge but find it difficult to put the learned knowledge into practice this was fully supported by Omorepie (2003) who reported that majority of youths are aware that HIV/AIDS exist, there exists an underestimation of personal risk. The question is why is the implementation of this knowledge difficulty? It may be due to hypersensitivity or hypersexual activity of the young people (students), Olawale, (2001) opined that perception, thinking pattern, attitude and belief about an issue can have an impact on observable behaviour.

The study has also revealed that slightly over half of the students use abstinence as a preventive measure, but some of these would stop abstaining if partners promise marriage. This is further compounded by the fact that some students found it difficult to abstain or avoid sex before marriage. Again the problem of trust comes into play. Once students promise each other marriage trust begins, and they end up indulging in unprotected sex. This is not safe.

The results also revealed that some of the students were using condoms for HIV and AIDS prevention. This is similar to what was said by Irin (2009) that condoms are an effective preventive measure for combating HIV and AIDS. But the use of condoms may not be consistent as it has emerged that students mainly use condoms with irregular partners. The inconsistency in the use of condoms was also confirmed in this study evidence by some of students getting pregnant while some contract sexually transmitted infections engaged in risky behaviour. This behaviour may be related to the trust they have with their partners, the trust is then misplacet. Giddens (2001) warned that there is a relationship between risk and trust. He argues that in a world of globalization is dangerous to trust as people did in village communities they used to live in. He therefore advises people to be cautious by his theory of social reflexivity. 'Social reflexivity refers to the fact that we have to constantly think about or reflect upon the circumstances in which we live our lives' (Gidden, 2001:680). Trusting sexual partners is a factor in HIV transmission. The more people trust the more chances that HIV is transmitted. The students' trust of their partners may lead them to HIV infection. This has a negative of effect on sustainable development.

Finally, according to the students, the teaching method for HIV and AIDS should be improved by using a variety of methods.

\section{Conclusion}

In conclusion, the result of this study revealed that although level of knowledge was high and risky taking behaviour was moderate among FUTA students but some students are still battling with other intervening factors and influences. Sometimes these factors and influences lead students to take risky sexual behaviours. Mainly is the danger of trusting partners whose status they do not know. Literatures also showed that HIV/AIDS 
is a real disease that has already killed a major number of young people (students). Efforts need to be made by government and non government organizations to help the students meet the challenges of HIV/AIDS. If not taken seriously, investment through education will achieve very little as most students may die before using their skills to develop themselves and future generations of Nigeria. It is therefore imperative for nurses to partner with appropriate agencies to find ways to help the students overcome the problem of HIV/AIDS by providing accurate and effective information that will bring a change in life styles needed for realistic and appropriate behaviour.

\section{Recommendations}

Based on the findings the following recommendations were made:-

1. Government should tram more nurses that would specialized in the management of HIV/AIDS infection.

2. Nurses should collaborate with university lecturer in giving information on HIV/AIDS through seminars, workshops and flyers. This would help the students change their behaviour.

3. The government should allow the entrenchment of sexuality education into the curriculum of all the schools in Nigeria this will help them to make the right choices. It will also make them to develop objective attitude to sex and make youths understand that there is no cure for HIV/AIDS.

4. Prevention message should be consistent clear and effective to counteract other unreliable.

\section{References}

[1]. Adedimeji, A. (2003) Perception of HIV/AIDS infection and condom use among Undergraduates in University, Department of Sociology University of Ibadan, Nigeria.

[2]. Atanazava A, Dimitrov G.O., Todorouskic, \& Samardziskil (2004) Knowledge about HIV/AIDS among teenage and adolescent female population in R. Macedonia international conference on AIDS; 2004 July 11-16;15.

[3]. Giddens, A. (2001) Sociology $4^{\text {th }}$ edition; Cambridge Blackwell.

[4]. Gulure M., (2003) A study of HIVS education programmes and activities of secondary schools. The case of selected schools in Zomba, Malawi. African Journal of Psychology 6: 928-931.

[5]. Irin (2009) Southern Africa: Focus on sex Education; An Antidote to HIV and AIDS (htt:www.Irinnews.org/report.aspx $(14 / 09 / 2009)$.

[6]. Jackson, H., (2002) AIDS Africa: Ac continent in Crisis Harare, SAFAIDS

[7]. Mental Health AIDS (2007): HIV Prevention News: About Adolescents and Young adults NEW /et. 8, 4:1 -11.

[8]. Ogundana, F. (2002) Attitude to death on obstacle to sexual behavioural change among men in urban Ekiti, Nigeria. Journal of counseling and Applied Psychology. 1(1) 56-67.

[9]. Olawale S.G. (2001) International to behaviours modification for undergraduates and helping professionals (Revised Edition) Ogbomoso, Nigeria. Adebayo Calvary press.

[10]. Anyamene, A., Nwokolo, C, Anyachebelu E., \& Okeke I.O. (2011) Influence of knowledge of HIV/AIDS on behaviour among adolescents, International Journal of Psychology \& counseling 3(8) pp 154-158.

[11]. Omoreple. G., (2003) Risk Perception of HIV/AID among youths in Nigerians abstract September (2003), A Nigerian Contribution to regional and global meeting on HIV/AIDS compiled by Nigerian Institute of Medical Research and National action on AIDS (NACA).

[12]. Robilland R.H. (2001) The Jamaccan Adolescent: An assessment of Knowledge and Attitude regarding HIV/AIDS Pediatric Nursing, 27(2): 176 .

[13]. Seligson M.r. \& Peterson, K.E. (1992) AIDS prevention and treatment, Humor and Healing, New York, Hemisphere publishing corporation.

[14]. Svenson, LW. Varnhagen CK, Godin AM, Salman (1992) Rural High School Students' Knowledge, Attitude and Behaviours related to sexually transmitted diseases. Canadan Journal or public health, 83: 260-263.

[15]. Tedro G. (2001) AIDS: The barriers to behaviour change. Double dag. New York pp. 1603-1622.

[16]. UNAIDS (2007) A cultural approach to HIV/AIDS prevention and Cane, pp 125-133. 